\title{
Complete Atrioventricular Block
}

National Cancer Institute

\section{Source}

National Cancer Institute. Complete Atrioventricular Block. NCI Thesaurus. Code C50501.

A disorder characterized by an electrocardiog raphic finding of complete failure of atrial electrical impulse conduction to the ventricles. This is manifested on the ECG by disassociation of atrial and ventricular rhythms. The atrial rate must be faster than the ventricular rate. (CDISC) 